\title{
Horizontal Transmission
}

National Cancer Institute

\section{Source}

National Cancer Institute. Horizontal Transmission. NCI Thesaurus. Code C127773.

The transmission of a disease from one individual to another. 